Please do not remove this page

RMIT

UNIVERSITY

\title{
Morphological, mechanical, and thermal characterization of biopolymer composites based on polylactide and nanographite platelets
}

Narimissa, Esmaeil; Gupta, Rahul; Choi, Hyoung; Kao, Nhol; Jollands, Margaret

https://researchrepository.rmit.edu.au/esploro/outputs/9921858670301341/filesAndLinks?institution=61RMIT_INST\&index=null

Narimissa, E., Gupta, R., Choi, H., Kao, N., \& Jollands, M. (2012). Morphological, mechanical, and thermal characterization of biopolymer composites based on polylactide and nanographite platelets. Polymer Composites, 33(3), 1505-1515. https://doi.org/10.1002/pc.22280

Document Version: Submitted Version

Published Version: https://doi.org/10.1002/pc.22280

Repository homepage: https://researchrepository.rmit.edu.au

(c) 2012 Society of Plastics Engineers

Downloaded On 2023/04/26 20:45:11 +1000 
Thank you for downloading this document from the RMIT Research Repository.

The RMIT Research Repository is an open access database showcasing the research outputs of RMIT University researchers.

RMIT Research Repository: http://researchbank.rmit.edu.au/

\section{Citation:}

Narimissa, E, Gupta, R, Choi, H, Kao, N and Jollands, M 2012, 'Morphological, mechanical, and thermal characterization of biopolymer composites based on polylactide and nanographite platelets', Polymer Composites, vol. 33, no. 3, pp. 1505-1515.

See this record in the RMIT Research Repository at:

http://researchbank.rmit.edu.au/view/rmit:17147

Version: Submitted Version

Copyright Statement: (c) 2012 Society of Plastics Engineers

Link to Published Version:

http://dx.doi.org/ 10.1002/pc.22280 


\title{
Morphological, Mechanical, and Thermal Characterization of Biopolymer Composites Based on Polylactide (PLA) and Nanographite Platelets
}

\author{
Esmaeil Narimissa, Rahul K Gupta*, Hyoung J. Choi^, Nhol Kao and Margaret Jollands \\ Rheology and Materials Processing(RMPC) Centre, School of Civil, Environmental and Chemical \\ Engineering, RMIT University, 124 Trobe St, Melbourne, Vic 3000, Australia \\ ${ }^{\wedge}$ Department of Polymer Science and Engineering, Inha University, Incheon, 402-751 Korea \\ *Corresponding Author: E-mail: rahul.gupta@rmit.edu.au
}




\begin{abstract}
This work focuses on development and optimization of polylactide (PLA) and nanographite platelets (NGP) based composites to display possible superior mechanical and improved thermal stability. Melt blending and dry mixing methods of fabrication were employed at temperature of $180{ }^{\circ} \mathrm{C}$. Different Loading fractions of NGP were incorporated into polymer matrix. Morphological evaluation techniques such as XRD and TEM were applied to determine the degree of dispersion of NGPs into PLA matrix. Mechanical properties were evaluated and correlated to structural morphologies of PLA/NGP composites. Thermal properties of composites were studied to examine possible changes in $T_{g}, T_{c}, T_{m}$, and percentage crystallinity of these composites. The effect of mixing was also explored through double extrusion of some samples. It was concluded that composites containing 3 wt. \% NGP showed optimum mechanical performance without any significant changes in the thermal characteristics.
\end{abstract}




\section{INTRODUCTION}

Research in the field of bionanocomposites can potentially be beneficial in increasing the efficiency of recycling waste management and greenhouse emissions. The synergistic assembly of nanoadditives and biopolymer properties provide industry and its prospective technologies with many new possible methods of reducing greenhouse emissions, enhancing waste management and improving sustainability $[1,2]$. Polylactide (PLA) is currently receiving considerable attention for conventional use, due to its beneficial qualities, which include being biodegradable, produced from renewable resources and used for numerous functions such as packaging materials, production of fibres and composites for technical applications [3-6]. Furthermore, There has been a recent increase in the production of PLA due to its high demands from packaging manufacturers ,as well as, PLA's application as the base material for devices such as suture fibers and scaffolds in the area of tissue engineering [7].

PLA is produced by catalytic and thermolytic ring-opening polymerization of lactide to polylactide, Therefore, the primary component of PLA is very likely to undergo thermal degradation during processing, hence, efficient drying $(<250 \mathrm{ppm})$ is required prior to melt blending process [8]. PLA is also applicable in engineering utilizations such as, electronic and electrical devices, mechanical and automotive parts. This will require improvements to PLA properties using such methods as combining this polyester matrix with different dispersed phases such as impact modifiers, flameretardants, plasticizers, nanofillers and other polymers $[9,10]$. Melt blending PLA with other nanofillers has been shown to produce nanocomposites with improved properties such as stiffness, thermal stability, fire retardancy and lower gas permeability [11, 12]. For instance, Karger-Kocsis research found that clay could have both reinforcing and polymorphism inducing effect on such biodegradable polymers [13-15]. Besides, The crystallization rate and orientation in crystallinity has been shown to enhance in nylon-6-clay $[16,17]$. Moreover, Carbon nanotubes (CNTs) have proven to act as nucleating agent enhancing crystallization temperature and rate of neat polypropylene [18]. Nanosized carbonous filled polymer composites showed remarkable improved mechanical, fire resistance, and electrical conductivity and barrier properties [19]. Nanographite platelets (NGPs) 
combine the platelets structure, low price of clay as well as greater electrical and thermal properties of carbon nanotubes, which may improve the crystallization behaviour of PLA. Unlike CNTs and carbon nanofibres (CNFs) which are long and thin, NGPs do not entangle with each other, reducing the tendency for agglomeration.

Another advantage of NGP over carbon fillers such as carbon black and fibers is its ability to improve the properties of the composites at smaller loading. The highest thermal conductivity discovered so far in the research literature belongs to nanographene materials (six times that of copper) allowing faster thermal dissipation [20]. NGPs are similar to copper in terms of electrical conductivity while having only one-fourth of the density of copper and in terms of mechanical strength, NGPs are fifty times stronger than steel [21, 22]. In addition, it has been reported that graphite platelets can induce the nucleation of $\beta$-form polypropylene (PP) crystals, which is superior to more common $\alpha$-form crystals [23]. NGPs are also useful substitute for both clays and CNTs in polymer nanocomposites and are well suited to applications that require heat stability, lubricant ability, thermal and electrical conductivity. More specifically, graphite consists of graphene nanosheets and has thermal and electrical characteristics that are more commonly associated with metals $[19,24]$. However, some limitations of NGPs application are the poor control over their dispersion and orientation, their low solubility in organic solvents and polymers, in addition to the strong molecular binding between their stacks, which restrains their functionality in composite fabrication [25].

The current study explores the effect of loading fraction and mixing process of nanographite platelets (NGPs) on mechanical and thermal performance of Polylactide (PLA) biopolymer. Morphological properties of composites are also investigated to provide better understanding of the dispersion of NGP into the polymer matrix. 


\title{
EXPERIMENTAL
}

\section{Materials}

Poly(L,L-lactide)- (PLA) was supplied by NatureWorks LLC. The grade used was 3051D [26]. Nanographite platelets (NGPs) were supplied by XG Sciences, Inc US Michigan. The grade of NGP used for this study was "M" with characteristics: average thickness of approximately 6 - 8 nanometers and a typical surface area of 120 to $150 \mathrm{~m}^{2} \mathrm{~g}^{-1}$. Grade $\mathrm{M}$ is available with average particle diameters of 5,15 or 25 microns [27].

\begin{abstract}
Drying
Drying to less than $250 \mathrm{ppm}$ is necessary earlier before processing[26]. PLA pellets used in this study were dried in a fan dryer at a temperature of $50{ }^{\circ} \mathrm{C}$ for 7 days before melt blending through extruder.
\end{abstract}

\section{Physical Dry Mixing}

PLA pellets and nanographite platelets (NGP) were dry blended in the desired composition prior to melt blending in 700 gram batches. Table 1 shows the compositions and the codes of neat PLA and PLA/NGP samples. Hereafter, samples are referred according to their sample codes.

\section{Extrusion, Pelletization, and Compression Moulding of Composites}

Samples were melt-blended in a Brabender Twin Screw extruder in ambient condition. The speed and temperature of the extruder for melt blending of samples were set at $180{ }^{\circ} \mathrm{C}$ and $40 \mathrm{RPM}$ which was reported as the optimum mixing condition in the same extruder for the fabrication PLA/organoclay nanocoposite [28]. Too high or low extrusion temperature or speed may cause thermal degradation and/or insufficient shear for proper mixing of nanocomposites. Afterward, neat 
PLA as well as PLA03 samples were double extruded. These extruded composites were pelletized then were sealed in plastic bags and stored in a vacuum oven before further processing.

Dried pellets were compression moulded into dog bone-shaped ASTM D638 mechanical testing specimens. The compression moulding temperature was $180{ }^{\circ} \mathrm{C}$ and the compression force was kept at $80 \mathrm{kN}$ for 5 minutes. Cooling water was used to cool the moulding press from 180 to $50{ }^{\circ} \mathrm{C}$. Eight specimens were prepared for each sample for mechanical testing.

\begin{abstract}
Storage
Samples were stored in a vacuum oven at $50{ }^{\circ} \mathrm{C}$. Portable desiccators containing silica gels were used to carry the samples from the vacuum oven to processing and various characterization instruments.
\end{abstract}

\title{
Characterization
}

\section{Morphological Evaluations (XRD and TEM)}

Wide angle X-ray (WAXS), a Rikaku X-ray diffractometer (the wavelength of $0.154 \mathrm{~nm}$ ) with $40 \mathrm{kV}$ accelerating voltage and $40 \mathrm{~mA}$ current for recording data within a range of $2 \theta=10 \sim 80^{\circ}$. Bragg's equation (eq. 1) was utilized to interpret the XRD data:

$$
n \lambda=2 d \sin (\theta)
$$

Where $\mathrm{n}$ is the order of reflection, $\lambda$ is the wavelength of radiation, $\mathrm{d}$ is the interlayer or $\mathrm{d}$-spacing and $\theta$ is the half scattered angle [29].

Transmission electron microscopy (TEM) images were obtained with a Phillips CM200 operated at an acceleration voltage of $120 \mathrm{kV}$. The samples were ultramicrotomed using a RMC ultramicrotome with CR-X Cryosection at $-160{ }^{\circ} \mathrm{C}$. TEM micrographs were printed on A4 sheets and the filler dimensions were measured and analyzed according to the image magnification of $0.2 \mu \mathrm{m}$. 


\section{Mechanical Testing Measurements}

Tensile testing measurements were performed using an Instron 4467 Universal testing machine in accordance to ASTM D638M norm at speed rate of $1 \mathrm{~mm} / \mathrm{min}$ using a distance of $115 \mathrm{~mm}$ between grips and the extensometer was set at 50mm separation. Measurements were carried out at ambient temperature.

\section{Modulated Differential Scanning Calorimetry (MDSC)}

Thermal property characterization of nanocomposites was performed by modulated temperature differential scanning calorimeter (MDSC) with a TA Instrument Model 2920. Samples were heated and cooled in nitrogen atmosphere. Samples of approximately 7-9 mg in weight were encapsulated in aluminium pans. An empty sealed aluminium pan and lid was used as the reference. The first heating scan was run at $2{ }^{\circ} \mathrm{C} \min ^{-1}$ and modulated at $\pm 0.5{ }^{\circ} \mathrm{C} / 40 \mathrm{sec}$ from $0{ }^{\circ} \mathrm{C}$ up to $200{ }^{\circ} \mathrm{C}$. It was held at this temperature for 2 minutes, and then the first cooling scan was run at $2{ }^{\circ} \mathrm{C} / \mathrm{min}$ down to 0 ${ }^{\circ} \mathrm{C}$. The second heating scan was also run from 0 to $200{ }^{\circ} \mathrm{C}$ at $2{ }^{\circ} \mathrm{C} \min ^{-1}$. The first scan erased the thermal history of PLA/NGP nanocomposites. In order to minimize the possible effect of nonuniformity of the micro-size DSC specimens, the reproducibility of the result was examined through three specimens in each sample.

\section{RESULTS AND DISCUSSION}

\section{Morphological Properties}

The possible development of crystalline structure and the structure of nanofillers were studied using XRD and TEM. The diffractograms recorded for the samples at ambient condition are illustrated in Fig. 1. The diffractograms demonstrate an intense peak at $2 \theta$ value of $\sim 26.4^{\circ}$ assigned to single nanographite platelet layers at a distance of $0.341 \mathrm{~nm}$, which has been detected at very similar $2 \theta$ for graphite sheets in a number of earlier studies [30-32]. This observation verifies the occurrence of the same d-spacing of graphite layers in all composites, as well as suggesting that the meltblending process did not separate the graphite layers, with the majority of them still present in aggregate structure. This may be due to the strong bond between graphite sheets that kept them 
interlinked with one another and made exfoliation of NGP layers relatively difficult [19]. NGP fragility is a major limitation during the delamination of graphite sheets through melt blending with PLA, which could result in the breakdown of graphite sheets. Consequently, adequate delamination may not be possible in melt blending process and yet improved mixing conditions seem to be ineffective in this regards and dense stacking of graphite layers is unavoidable [30]. According to Yasmin et al. [33], such peaks $\left(2 \theta \sim 26.4^{\circ}\right)$ can be attributed to fewer remaining aggregates and reduced layers of graphite sheets. The diffractograms also show scattered intensity distribution with a broad maximum around $2 \theta \sim 16.5^{\circ}$ in composites, suggesting a semi crystalline structure of PLA. However, the intensity of the peaks differed in neat PLA and different composites. The peak was more accentuated in PLA01 sample, reasons for which could be attributed to the swelling of the graphite structure during extrusion and compression moulding of composites. A recent study by Pluta [34] found that at temperatures higher than cold crystallization temperature $\left(\mathrm{T}_{\mathrm{c}}\right), \mathrm{XRD}$ diffractograms show crystalline peaks located at the same angle $\left(2 \theta \sim 16.5^{\circ}\right)$. However, he ascribed these peaks to the $\alpha$ crystalline form of PLA classified as pseudo-orthorhombic modifications that can be formed even during the rapid cooling in the final step of the compression moulding process.

Results also showed that diffractograms of double extruded samples (2X (neat PLA) and 2X (PLA03)) did not exhibit noticeable difference with their single extruded counterpart (Fig. 1b) indicating similar degree of dispersion. It should be taken into account that the difference in the height (intensity) of sharp peaks $\left(2 \theta \sim 26.4^{\circ}\right)$ is only due to the scaling the picks in order to plot them on top of each other.

Fig. 2 shows TEM images of composites at $0.2 \mu \mathrm{m}$ magnification. Compared to particle size of 25 $\mu \mathrm{m}$ (provided in material data sheet), the nanofillers dispersion can be considered sufficient. Presence of mixed morphology (combination of intercalated and dispersed single layers of individual graphite sheets) is evident in the micrographs (Fig. 2 a, f) and the lengths of these nanolayers can reach to hundreds of nanometers. Nevertheless, the observation of a single exfoliated nanofiller platelet in TEM image does not indicate comprehensive delamination of NGP 
in PLA matrix. In addition, the tactoid presence is noticeable in PLA03 to PLA10 composites, which suggests that the sharp peaks at $\left(2 \theta \sim 26.4^{\circ}\right)$ in Fig. 1 can be the consequence of the formation of tactoids and agglomerates of NGP layers in samples. Moreover, all TEM micrographs illustrate some perpendicular orientation of platelets $(\sim 20-50 \mathrm{~nm}$ thickness $)$ to images' surface area $(2.1 \mu \mathrm{m}$ $\mathrm{X} 2.1 \mu \mathrm{m})$. The TEM images do not show noticeable alteration in average thickness of graphite platelets in comparison to the previously reported untreated sheets estimated from AFM analysis $(37 \mathrm{~nm})$ and BET (Brunauer, Emmett and Teller) surface area assuming disk-like morphology (30 $\mathrm{nm})[25,35]$. Likewise, the occurrence of small sharp peaks at $2 \theta \sim 54^{\circ}\left(\mathrm{d}_{004}\right.$ orientation) for PLA01 to PLA10 samples (Fig. 1a) may be ascribable to the partial break up of graphite sheets during the melt blending process. According to Schniepp et al. [36] exfoliated functionalized graphite sheets layers exhibit an average thickness of $\sim 1.8 \mathrm{~nm}$. However, the TEM images of the current study found the thickness of graphite layers to only be as low as $\sim 8 \mathrm{~nm}$ (Fig. 2 a, d, e, h), which is compatible with the thickness of a few stacked sheets.

TEM images of single extruded and double extruded composites with 3 wt. \% NGP content shown in Fig. 3 display the effect of mixing. The decrease in thickness of graphite layers and their tactoid size (compare Fig. 3c, d with Fig. 3a, b) suggests that an improved dispersion of nanofiller in polymer matrix occurred through the double extrusion process. However, the desirability of this improvement is subjected to mechanical and thermal property alterations and is to be discussed in forthcoming sections of this study. Rumples were also observed in some micrographs (Fig. 2 c, e), which could possibly be due to the transformation of planar graphite carbons ( $\mathrm{sp}^{2}$ hybridization) to out of plane carbons $\left(\mathrm{sp}^{3}\right.$ hybridization) through oxygen surface functionalities as a result of oxidation and pyrolysis process, instigating the structural distortion, weakening of the planar geometry and subsequently the bending of the sheets [25, 35]. Such conversions were observed by Kudin et al. and Kim and Macosko as higher graphite lattice ( $\mathrm{G}$ band) to graphite edges (D band) intensity ratio of functionalized graphite sheets (FGS) in Raman spectroscopy and X-ray photoelectron spectroscopy (XPS) [35, 37]. The stacking of these rumpled sheets as well as 
inadequate thermal exfoliation and oxide intercalation could be the major reasons behind the unexpected presence of tactoids in composites with filler contents as low as 3 wt. \% (PLA03). Despite the NGP thickness of 6-8 $\mathrm{nm}$ (provided by the material data sheet), the morphological analysis of this study indicates that utter exfoliation is not achievable under melt blending and dry mixing. Thus, dominant tactoid formation in coexistence with minor intercalation and negligible platelet individualization could be the only conceivable outcome of the morphological investigation of this study. Unlike nanofillers such as organically modified layered silicate (OMLS), melt blending and dry mixing processes may not be capable of efficient dispersion and individualization of graphite layers. Thus, through the mixing process, PLA/NGP samples may only be identified as microcomposites and not nanocomposites.

\section{Mechanical Properties}

Certain properties of samples such as tensile and flexural strength, Young's modulus and dimensional stabilities are expected to be improved as a result of incorporation of nanofillers into polymer matrix. Figs. 4-6 demonstrate the mechanical properties of composites compared to neat PLA, wherein the amount of nanofiller (NGP) increased up to $10 \mathrm{wt}$ \%. Double extruded samples of neat PLA and PLA03 are shown as 2X (neat PLA) and 2X (PLA03). The Sample at the optimum filler level (PLA03) was extruded twice to test the effect of longer residence time on mixing and mechanical properties. As shown in Table 2, the incorporation of NGP into PLA significantly increased the Young's modulus. PLA03 sample had the highest modulus, 135\% higher than the base polymer (Fig. 4). The utmost value of NGP content (3 wt. \% here) at which Young's modulus reaches its maximum is regarded as critical loading or mechanical percolation threshold. Besides, The optimum around 3 wt. \% nanofiller is consistent with the percolation threshold reported for platey nanocomposites [38]. A gradual decrease in modulus was observed for filler contents of 510 wt. \%. According to the TEM micrographs (Fig. 2), this decline in modulus might be attributed to the tendency of NGP particles to aggregate at higher loadings. However, the actual mechanism of this effect is under rheological investigation and it will be reported soon. Table 2 also displays the 
standard deviation of the samples. Another indication of the occurrence of mechanical percolation threshold at around 3 wt. \% NGP is indicated by the large increase in standard deviation (and consequently standard error) of PLA03 compared to the rest of the samples (as shown in Fig. 4 and Table 2). Indeed, mechanical properties can potentially be further enhanced if the mixing process were improved. Young's modulus of the twice extruded neat PLA (2X (neat PLA)), was similar to its once extruded counterpart. This pattern of findings indicates that the neat PLA was thermally stable even though the residence time was doubled. However, the Young's modulus of 2X(PLA03) was significantly lower than the once extruded sample, which could be due to the thermal degradation of double extruded composites due to the presence of NGP in polymer matrix. The addition of platey fillers will increase the viscosity and subsequently, the effect of longer residence time may be different for PLA/NGP composites from neat PLA. However, the standard deviation of 2X (PLA03) was drastically reduced, which is an indication of the expected improved mixing. This was confirmed by TEM micrographs showing smaller tactoids in 2X (PLA03) compared to PLA03 (Fig. 3).

According to Fig. 5, as a result of increasing NGP contents in neat PLA, tensile strength gradually decreased in composites. This may be attributed to weak regions in matrix-filler system where loops in several chains are in close proximity, but do not entangle with one another [39]. These aggregates of chain ends also cause microcracks at the interface and lower the available matrixfiller interaction [40]. Furthermore, higher concentrations ( $>3 \mathrm{wt} . \%$ ) of NGP might have resulted in larger amount of NGP to be present between the interface. In contrast, the double extruded samples do not show any remarkable differences with their single extruded counterparts in this regard.

As Fig. 6 illustrates, the addition of NGP caused a decrease in elongation at break for composites. Thellen et al. [41] reported that the addition of filler to a plastic usually would decrease the elongation considerably and this behaviour could be attributed to the aggregation of nonintercalated fillers in the composites that increases the embritterment. Hence, possibly due to large 
interaction formed between polymer and NGP at low concentration, mobility of the chains was restricted; whilst because of the aggregation of NGP particles at higher concentration in composites, percentage elongation was not improved; as expected. Therefore, percentage elongation at break decreased as NGP content was increased.

Overall, the findings of the current study indicated that composites' elasticity (Young's modulus) and tensile strength (only at low concentration) were improved to the detriment of percentage elongation at break (in comparison to neat PLA up to PLA03). Moreover, the double extrusion of 0 and 3 wt. \% NGP content samples were found not to considerably vary the elongation at break and tensile strength of composites (refer to Fig. 5, 6).

\section{Thermal Properties}

During heat scanning of the samples via MDSC technique, the following characteristics of the samples were determined: glass transition temperature $\left(T_{g}\right)$, melt temperature $\left(T_{m}\right)$, cold crystallization temperature $\left(\mathrm{T}_{\mathrm{c}}\right)$, endothermic enthalpy of melting $\left(\Delta \mathrm{H}_{\mathrm{m}}\right)$, and exothermic enthalpy of crystallization $\left(\Delta \mathrm{H}_{\mathrm{c}}\right)$. The MDSC results of second heating cycle are shown in Table 3 . The implication of this cycle was to eliminate the sample's preceding thermal history during the first heating cycle. The following equation was applied to calculate the percentage crystallinity [42]:

$$
\% \text { Crystallinity }=X_{c}=100 \times \frac{\Delta H_{m}}{\Delta H_{m}^{\infty}}
$$

Where $\Delta \mathrm{H}_{\mathrm{m}}$ is the enthalpy of fusion and $\Delta H_{m}^{\infty}$ is the heat of melting of $100 \%$ crystalline polymer and $X_{\mathrm{c}}$ is the percentage crystallinity. The theoretical melting enthalpy of $100 \%$ crystalline PLA was taken to be $\Delta H_{m}^{\infty}=93 \mathrm{~J} \mathrm{~g}^{-1} \quad$ [43]. No significant change in $\mathrm{T}_{\mathrm{g}}$ of the samples was found, as it remained fairly constant (entries 1-8) at about $60{ }^{\circ} \mathrm{C}$. Melting temperature of single extruded composites showed small difference with neat PLA (when $\mathrm{T}_{\mathrm{m}}$ of neat PLA $=150{ }^{\circ} \mathrm{C}$ ) (entries 1-6). 
However, according to Cser et al. [44], $\mathrm{T}_{\mathrm{m}}$ can be measured to $+/-0.5{ }^{\circ} \mathrm{C}$. Therefore, the minor decrease in $\mathrm{T}_{\mathrm{m}}$ and percentage crystallinity questions the role of graphite sheets as nucleating agent. Drazel group (supplier of $\mathrm{xGnP}$ for this study) reported similar findings on their PP/NGP nanocomposites [23]. They considered such reductions insignificant and argued that the initiation of crystallization at higher temperature $\left(\mathrm{T}_{\mathrm{c}}\right)$ at higher NGP content, confirmed the nucleating effect of NGP. Such increases (in $\mathrm{T}_{\mathrm{c}}$ ) were observed in the current study only for 1,3 , and 7 wt. $\%$ filler content (entries 2, 3 and 5). However, the validity of that claim is yet to be investigated.

The occurrence of two exothermic peaks at $\mathrm{T}_{\mathrm{m}}$ reflected the melting of crystalline regions of various sizes and perfections, which could indicate the existence of copolymer of L and D isomers in the PLA supply. NGP also had a noteworthy effect on the behaviour of melting peaks. It resulted in melting peaks becoming narrower and more stretched in composites compared to neat PLA (Fig. 7a), which suggests that the crystals are thinner and more homogenous in composites than in neat PLA samples[23].

PLA05 sample showed the highest enthalpy of fusion and percentage crystallinity among other composites (PLA01, PLA03, PLA07, and PLA10). Findings also showed that the percentage crystallinity decreased at PLA01 and PLA03 composites, consistent with the findings of Gopakumar et al. [45], reporting a decline in percentage crystallinity upon the exfoliation of clay platelets. They accredited this decrease in percentage crystallinity to higher interfacial area and adhesion between the polymer and the clay, which acted to reduce the mobility of crystallisable chain segments and consequently the time of agglomeration of fillers. However, according to XRD and TEM results of the current study, major exfoliation was not achieved and tactoid formation combined along with intercalation and limited exfoliation at graphite contents over $3 \mathrm{wt}$. \% could be the only valid argument for the extent of dispersion of nanofillers. Conversely, percentage of crystallinity and enthalpy of fusion of PLA07 and PLA10 samples showed no enhancement compared to neat PLA, and were the lowest values among other composites. One explanation of the 
pattern of findings is that the mechanical percolation threshold region is somewhere between 3 to 5 wt. \% filler content. The uppermost heat of fusion of composites was also observed for PLA05 and further addition of nanofiller initiated distinct falls in percentage crystallinity of PLA07 and PLA10 samples.

Double extruded neat PLA showed 6\% decrease in percentage crystallinity compared to single extruded neat PLA sample, and only 5.4\% reduction in percentage crystallinity was detected for $2 \mathrm{X}$ (PLA03) NGP composite. Cold crystallization temperatures $\left(\mathrm{T}_{\mathrm{c}}\right)$ of double extruded composites significantly decreased $\left(\sim 10^{\circ} \mathrm{C}\right)$ compared to their single extruded counterparts, though, minor $(\sim 1$ $\left.{ }^{\circ} \mathrm{C}\right)$ and noteworthy $\left(\sim 5{ }^{\circ} \mathrm{C}\right)$ increases occurred at glass transition and melting temperatures of double extruded samples respectively (Table 3, Fig. 7b).

An additional measure of nucleating agent effectiveness is the crystallization half-time $\left(\mathrm{t}_{1 / 2}\right)$ in the isothermal crystallization experiment. Crystallisable polymer matrix such as PLA, PP, PHB and polyamides have previously been shown to be nucleated by graphite under isothermal conditions [43]. Forthcoming studies will explore the nucleating effects of NGP on PLA through crystallization half-time $\left(\mathrm{t}_{1 / 2}\right)$ at peak of hot crystallization temperature of $110{ }^{\circ} \mathrm{C}$. Table 4 and Fig. 7c show MDSC data and their corresponding micrograms of samples during the first heating cycle when the thermal history was still present. The absence of pre-melting endotherm in the first heating cycle (Fig. 7c) before cold crystallization exothermic peak signifies that thermal destruction of weakly ordered regions did not occur throughout the aging process of the samples (i.e. during the 3 week storage period prior to testing) [34]. Fig. 7c also demonstrates the existence of an endotherm following the glass transitions step change (illustrated as an extension to the $\mathrm{T}_{\mathrm{g}}$ of the second heating cycles) at lower temperature range $\left(50-60{ }^{\circ} \mathrm{C}\right)$. This endotherm is generally attributed to enthalpic relaxation, which has been described in the literature using such terms as: middle endothermic peak, volume relaxation and stress relaxation. The magnitude of this endotherm is dependent on the thermal history of samples and rises with time of aging upon enhanced temperature and even to the level below the $\mathrm{T}_{\mathrm{g}}$ of PLA $[34,46,47]$. 
Figure $8(\mathrm{a}, \mathrm{b})$ illustrates the cooling thermograms of composites after the first heating cycle. It indicates that all samples reveal a weak crystallization effect during the cooling cycle (at approximately $111^{\circ} \mathrm{C}$ ), which cannot be due to the slow cooling ramp of $2{ }^{\circ} \mathrm{C} \mathrm{min}^{-1}$ that somewhat enhances the melt quenching effect. Table 5 shows the cooling cycle data of single and double extruded composites gathered from MDSC thermograms. A similar trend in percent crystallinity was observed in the first cooling cycle, compared to both heating cycles. The crystallinity amount during heating and cooling cycle indicate that most of the crystallization occurred during heating cycle; however, self- nucleation might have happened during cooling cycle only. Therefore, most of crystallization growth occurred during heating cycle between $\mathrm{T}_{\mathrm{g}}$ and $\mathrm{T}_{\mathrm{c}}$ as expected.

Overall, thermal analysis results suggest that NGPs are not only poor nucleators but they also decrease nucleation and subsequently crystallization to some extent. This cannot be due to lower degree of dispersion, lack of exfoliation, or insufficient intercalation since if it was, it would have affected the crystallization during heating and cooling cycles in the same manner. They may bond to polymer molecules and hold them tightly without any initiation of nucleation, thus, polymer molecules cannot move to crystallize in a similar behaviour as when the sample temperature drops below glass transition temperature. A better understanding of nucleating behaviour of NGPs can be achieved through isothermal crystallization analysis of samples at a temperature above their cold crystallization temperature which can explain the rate via half-time of crystallization and the dimensions of growth of crystals through the Avrami equation. 


\section{CONCLUSION}

Nanographite platelets (NGP) were melt blended into PLA matrix at different filler contents. Morphological analysis of the composites did not exhibit exfoliation or even high level of intercalation of nanofillers into polymeric matrix. However, partial exfoliation and limited break down of platelets were detected. Mechanical testing showed significant improvement of Young's modulus at 3 wt. \% filler content (PLA03). Double extruded samples showed improved level of mixing of nanofillers into polymer, which was demonstrated by a reduction in tactoid size of TEM images and a drop in the standard deviation of their Young's modulus. The significant decrease in the modulus of $2 \mathrm{X}$ (PLA03) indicated that the thermal degradation of the composites due to longer residence time was likely to occur in the presence of NGP. Furthermore, thermal properties of the composites did not show improvements compared to neat PLA. The percentage crystallinity slightly decreased as a result of NGP incorporation into neat PLA. The highest crystallinity and enthalpy of fusion among composites were observed when the content of NGP was at 5 wt. \% (PLA05). Moreover, NGP did not demonstrate nucleating agent role on the polymer matrix and on the other hand it decreased the crystallization slightly. Finally, it is evident that efficient dispersion of graphite layers may not be achievable through melt compounding only.

\section{ACKNOWLEDGMENT}

The authors appreciate Mr. Michael Allan (senior research assistant at RMIT) for his kind technical assistance and valuable comments throughout this study. We also thank Prof. Robert Shanks (professorial fellow at school of applied science of RMIT) for his advices in thermal analysis of the samples. 


\section{$\underline{\text { Table Captions }}$}

Table 1. Compositions of PLA/NGP composites and their corresponding sample codes.

Table 2. Young's modulus, standard deviation (STD) and STD/mean\% of composites.

Table 3. MDSC data of neat PLA and PLA/NGP composites (second heating cycle with a ramp of $\left.2{ }^{0} \mathrm{C} / \mathrm{min}\right)$

Table 4. MDSC data of neat PLA and PLA/NGP composites (first heating cycle with a ramp of 2 $\left.{ }^{0} \mathrm{C} / \mathrm{min}\right)$.

Table 5. MDSC data of neat PLA and PLA/NGP composites (first cooling cycle with a ramp of 2 $\left.{ }^{0} \mathrm{C} / \mathrm{min}\right)$.

\section{$\underline{\text { Figure Captions }}$}

Fig. 1. Comparative XRD diffractograms of composites after compression moulding: 0-10 wt. \% NGP content (a), double extruded composites (b).

Fig. 2. TEM micrographs of PLA/NGP composites at $0.2 \mu \mathrm{m}$ magnification microtomed from compression moulded specimens: $1 \%$ NGP (a, b), 3\%(c, d), 5\%(e, f), 7\%(g, h), 10\%(i, j).

Fig. 3. TEM micrographs of PLA/NGP composites at $0.2 \mu \mathrm{m}$ magnification microtomed from compression moulded specimens: 3\% NGP (a, b), 2X (3\%NGP) (c, d).

Fig. 4. Young's modulus of samples measured through tensile testing. 
Fig. 5. Tensile strength of samples measured through tensile testing.

Fig. 6. Elongation of samples measured through tensile testing.

Fig. 7. Comparative MDSC thermograms of composites: (a) single extruded samples during second heating cycle (b) double extruded vs. their single extruded counterparts during second heating cycle (c) single extruded samples during first heating cycle.

Fig. 8. Comparative MDSC thermograms of composites: (a) single extruded samples during first cooling cycle (b) double extruded vs. their single extruded counterparts during first cooling cycle. 


\section{REFERENCES}

1. M. J. John and S. Thomas, Carbohydrate Polymers, 73, 3 (2008).

2. A. K. Mohanty, M. Misra, and L. T. Drzal, Natural fibers, biopolymers, and biocomposites, CRC, (2005).

3. E. T. H. Vink, K. R. Rábago, D. A. Glassner, and P. R. Gruber, Polymer Degradation and Stability, 80, 3 (2003).

4. D. Platt, Biodegradable polymers - market report, (2006).

5. R. E. Drumright, P. R. Gruber, and D. E. Henton, Advanced Materials, 12, 23 (2000).

6. P. Dubois and M. Murariu, JEC Composites Magazine, 45, 45 (2008).

7. N. Zhao, S. Shi, G. Lu, and M. Wei, Journal of Physics and Chemistry of Solids, 69, 5-6 (2008).

8. A. Södergård and M. Stolt, Progress in Polymer Science (Oxford), 27, 6 (2002).

9. M. A. Paul, M. Alexandre, P. Degée, C. Henrist, A. Rulmont, and P. Dubois, Polymer, 44, 2 (2003).

10. N. C. Bleach, S. N. Nazhat, K. E. Tanner, M. Kellomäki, and P. Törmälä, Biomaterials, 23, 7 (2002).

11. S. Solarski, M. Ferreira, E. Devaux, G. Fontaine, P. Bachelet, S. Bourbigot, R. Delobel, P. Coszach, M. Murariu, A. Da Silva Ferreira, M. Alexandre, P. Degee, and P. Dubois, Journal of Applied Polymer Science, 109, 2 (2008).

12. T. Villmow, P. Pötschke, S. Pegel, L. Häussler, and B. Kretzschmar, Polymer, 49, 16 (2008).

13. J. Karger-Kocsis, Polymer Engineering and Science, 36, 2 (1996).

14. J. Karger-Kocsis and J. Varga, Journal of Applied Polymer Science, 62, 2 (1996).

15. J. Karger-Kocsis, J. Varga, and G. W. Ehrenstein, Journal of Applied Polymer Science, 64, 11 (1997).

16. E. Devaux, S. Bourbigot, and A. El Achari, Journal of Applied Polymer Science, 86, 10 (2002).

17. P. Maiti and M. Okamoto, Macromolecular Materials and Engineering, 288, 5 (2003). 
18. A. R. Bhattacharyya, T. V. Sreekumar, T. Liu, S. Kumar, L. M. Ericson, R. H. Hauge, and R. E. Smalley, Polymer, 44, 8 (2003).

19. F. Hussain, M. Hojjati, M. Okamoto, and R. E. Gorga, Journal of Composite Materials, 40, 17 (2006).

20. H. Fukushima and L. T. Drzal, Annu. Tech. Conf. Soc. Plast. Eng., 61, (2003).

21. X. S. Du, M. Xiao, Y. Z. Meng, and A. S. Hay, Polymer., 45, (2004).

22. W. Zheng, X. H. Lu, and S. C. Wong, Appl. Polym. Sci., 91, (2004).

23. K. Kalaitzidou, H. Fukushima, P. Askeland, and L. T. Drzal, Journal of Materials Science, 43, 8 (2008).

24. D. D. L. Chung, Journal of Materials Science, 37, 8 (2002).

25. H. Kim and C. W. Macosko, Polymer, 50, 15 (2009).

26. NatureWorks, NatureWorks®PLA Polymer 3051D. 2006.

27. XGSciences, $x G n P ®$ Graphene Nanoplatelets - Grade $M$.

28. A. Bhatia, Experimental study of structure and properties biodegradable nanocomposites, in School of civil, environmental and chemical engineering. 2008, RMIT. p. 171.

29. E. Giannelis, R. Krishnamoorti, and E. Manias, Polymer-Silicate Nanocomposites: Model Systems for Confined Polymers and Polymer Brushes Polymers in Confined Environments, S. Granick, K. Binder, P. G. de Gennes, E. Giannelis, G. Grest, H. Hervet, R. Krishnamoorti, L. Léger, E. Manias, E. Raphaël, and S. Q. Wang, Editors. 1999, Springer Berlin / Heidelberg. p. 107-147.

30. M. Murariu, A. L. Dechief, L. Bonnaud, Y. Paint, A. Gallos, G. Fontaine, S. Bourbigot, and P. Dubois, Polymer Degradation and Stability, 95, (2010).

31. H. Kim, Y. Miura, and C. W. MacOsko, Chemistry of Materials, 22, 11 (2010).

32. E. Cappelli, S. Orlando, M. Servidori, and C. Scilletta, Applied Surface Science, 254, 4 (2007).

33. A. Yasmin, J. J. Luo, and I. M. Daniel, Composites Science and Technology, 66, 9 (2006).

34. M. Pluta, Polymer, 45, 24 (2004).

35. H. Kim and C. W. Macosko, Macromolecules, 41, 9 (2008). 
36. H. C. Schniepp, J. L. Li, M. J. McAllister, H. Sai, M. Herrera-Alonson, D. H. Adamson, R. K. Prud'homme, R. Car, D. A. Seville, and I. A. Aksay, Journal of Physical Chemistry B, 110, 17 (2006).

37. K. N. Kudin, B. Ozbas, H. C. Schniepp, R. K. Prud'homme, I. A. Aksay, and R. Car, Nano Letters, 8, 1 (2008).

38. M. Jollands and R. K. Gupta, Journal of Applied Polymer Science, 118, 3 (2010).

39. E. N. Lawrence and F. L. Robert, Mechanical Properties of Polymers and Composites, Marcel Dekker, (1994).

40. M. Karabulut, Production and Characterisation of Nanocomposite Materials from Recycled Thermoplastics, The Middle East Technical University, (2003).

41. C. Thellen, C. Orroth, D. Froio, D. Ziegler, J. Lucciarini, R. Farrell, N. A. D'Souza, and J. A. Ratto, Polymer, 46, (2005).

42. J. J. Kolstad, Journal of Applied Polymer Science, 62, 7 (1996).

43. A. M. Harris and E. C. Lee, Journal of Applied Polymer Science, 107, 4 (2008).

44. F. Cser, M. Jollands, P. White, and S. Bhattachary, Journal of Thermal Analysis and Calorimetry, 70, 2 (2002).

45. T. G. Gopakumar, J. A. Lee, M. Kontopoulou, and J. S. Parent, Polymer, 43, (2002).

46. B. Wunderlich, Thermal Analysis Of Polymeric Materials, Springer, (1990).

47. M. Todoki, Polymer Data Handbook (Japanese), (1986). 


\section{TABLES}

Table 1. Compositions of PLA/NGP composites and their corresponding sample codes.

Sample Code

\begin{tabular}{ccccccccc}
\cline { 2 - 8 } Sample Compositions & neat PLA & PLA01 & PLA03 & PLA05 & PLA07 & PLA10 & 2X (neat PLA) & 2X (PLA03) \\
\hline PLA content (wt. \%) & 100 & 99 & 97 & 95 & 93 & 90 & 100 & 97 \\
NGP content (wt. \%) & 0 & 1 & 3 & 5 & 7 & 10 & 0 & 3 \\
Times extruded (no.) & 1 & 1 & 1 & 1 & 1 & 1 & 2 & 2
\end{tabular}

Table 2. Young's modulus, standard deviation (STD) and STD/mean\% of composites.

\begin{tabular}{|c|c|c|c|}
\hline Sample Code & $\begin{array}{c}\text { Young's Modulus } \\
\text { (MPa) }\end{array}$ & $\begin{array}{c}\text { Standard } \\
\text { Deviation, (MPa) }\end{array}$ & (STD/Mean)\% \\
\hline neat PLA & 2300 & 200 & 8 \\
\hline PLA01 & 2600 & 370 & 14 \\
\hline PLA03 & 5400 & 1570 & 29 \\
\hline PLA05 & 4400 & 1010 & 23 \\
\hline PLA07 & 3000 & 700 & 23 \\
\hline PLA10 & 2600 & 370 & 14 \\
\hline 2X (neat PLA) & 2500 & 260 & 10 \\
\hline 2X (PLA03) & 2600 & 400 & 15 \\
\hline
\end{tabular}

Table 3. MDSC data of neat PLA and PLA/NGP composites (second heating cycle with a ramp of $\left.2{ }^{0} \mathrm{C} \min ^{-1}\right)$.

\begin{tabular}{cccccccc} 
Entry & Sample Code & $\left.\mathbf{T}_{\mathbf{g}}{ }^{\mathbf{0}} \mathbf{C}\right)$ & $\mathbf{T}_{\mathbf{c}}\left({ }^{\mathbf{0}} \mathbf{C}\right)$ & $\Delta \mathbf{H}_{\mathbf{c}}\left(\mathbf{J g}^{-\mathbf{1}}\right)$ & $\mathbf{T}_{\mathbf{m}}\left({ }^{\mathbf{0}} \mathbf{C}\right)$ & $\Delta \mathbf{H}_{\mathbf{m}}\left(\mathbf{J g}^{-\mathbf{1}}\right)$ & Crystallinity, $\%$ \\
\hline 1 & neat PLA & 59 & 116 & 29 & 150 & 30 & 32.8 \\
2 & PLA01 & 60 & 118 & 30 & 146 & 26 & 28.3 \\
3 & PLA03 & 59 & 117 & 31 & 151 & 25 & 27.4 \\
4 & PLA05 & 60 & 112 & 29 & 149 & 27 & 28.6 \\
5 & PLA07 & 60 & 111 & 25 & 149 & 24 & 25.4 \\
6 & PLA10 & 60 & 119 & 28 & 151 & 24 & 25.9 \\
7 & 2X (neat PLA) & 60 & 105 & 23 & 155 & 25 & 26.8 \\
8 & 2X (PLA03) & 60 & 108 & 27 & 155 & 25 & 27.4
\end{tabular}


Table 4. MDSC data of neat PLA and PLA/NGP composites (first heating cycle with a ramp of 2 $\left.{ }^{0} \mathrm{C} / \mathrm{min}\right)$.

2
3

\begin{tabular}{cccccccc} 
Entry & Sample & $\mathbf{T}_{\mathbf{g}}\left({ }^{\mathbf{o}} \mathbf{C}\right)$ & $\mathbf{T}_{\mathbf{c}}\left({ }^{\mathbf{0}} \mathbf{C}\right)$ & $\Delta \mathbf{H}_{\mathbf{c}}\left(\mathbf{J g}^{\mathbf{- 1}}\right)$ & $\mathbf{T}_{\mathbf{m}}\left({ }^{\mathbf{o}} \mathbf{C}\right)$ & $\Delta \mathbf{H}_{\mathbf{m}}\left(\mathbf{J g}^{-\mathbf{1}}\right)$ & Crystallinity, \% \\
\hline 1 & neat PLA & 63 & 107 & 26 & 155 & 26 & 27.7 \\
2 & PLA01 & 60 & 106 & 24 & 155 & 23 & 24.4 \\
3 & PLA03 & 62 & 108 & 27 & 155 & 24 & 26.1 \\
4 & PLA05 & 63 & 106 & 24 & 155 & 24 & 25.6 \\
5 & PLA07 & 61 & 103 & 20 & 155 & 22 & 23.3 \\
6 & PLA10 & 61 & 106 & 22 & 155 & 23 & 24.7 \\
7 & 2X (neat PLA) & 60 & 102 & 21 & 155 & 22 & 24.1 \\
8 & 2X (PLA03) & 63 & 103 & 22 & 155 & 22 & 24.0
\end{tabular}

Table 5. MDSC data of neat PLA and PLA/NGP composites (first cooling cycle with a ramp of 2 ${ }^{0} \mathrm{C} / \mathrm{min}$ ).

\begin{tabular}{ccccc}
\hline & & & & \\
Entry & Sample & $\left.\mathbf{T}_{\mathbf{c}} \mathbf{}^{\mathbf{}} \mathbf{C}\right)$ & $\Delta \mathbf{H}_{\mathbf{c}}\left(\mathbf{J g}^{-\mathbf{1}}\right)$ & Crystallinity, \% \\
\hline 1 & neat PLA & 111 & 0.75 & 0.8 \\
2 & PLA01 & 112 & 0.55 & 0.6 \\
3 & PLA03 & 111 & 0.30 & 0.3 \\
4 & PLA05 & 112 & 0.43 & 0.5 \\
5 & PLA07 & 110 & 0.36 & 0.4 \\
6 & PLA10 & 111 & 0.36 & 0.4 \\
7 & 2X (neat PLA) & 111 & 0.43 & 0.5 \\
8 & 2X (PLA03) & 111 & 0.36 & 0.4
\end{tabular}



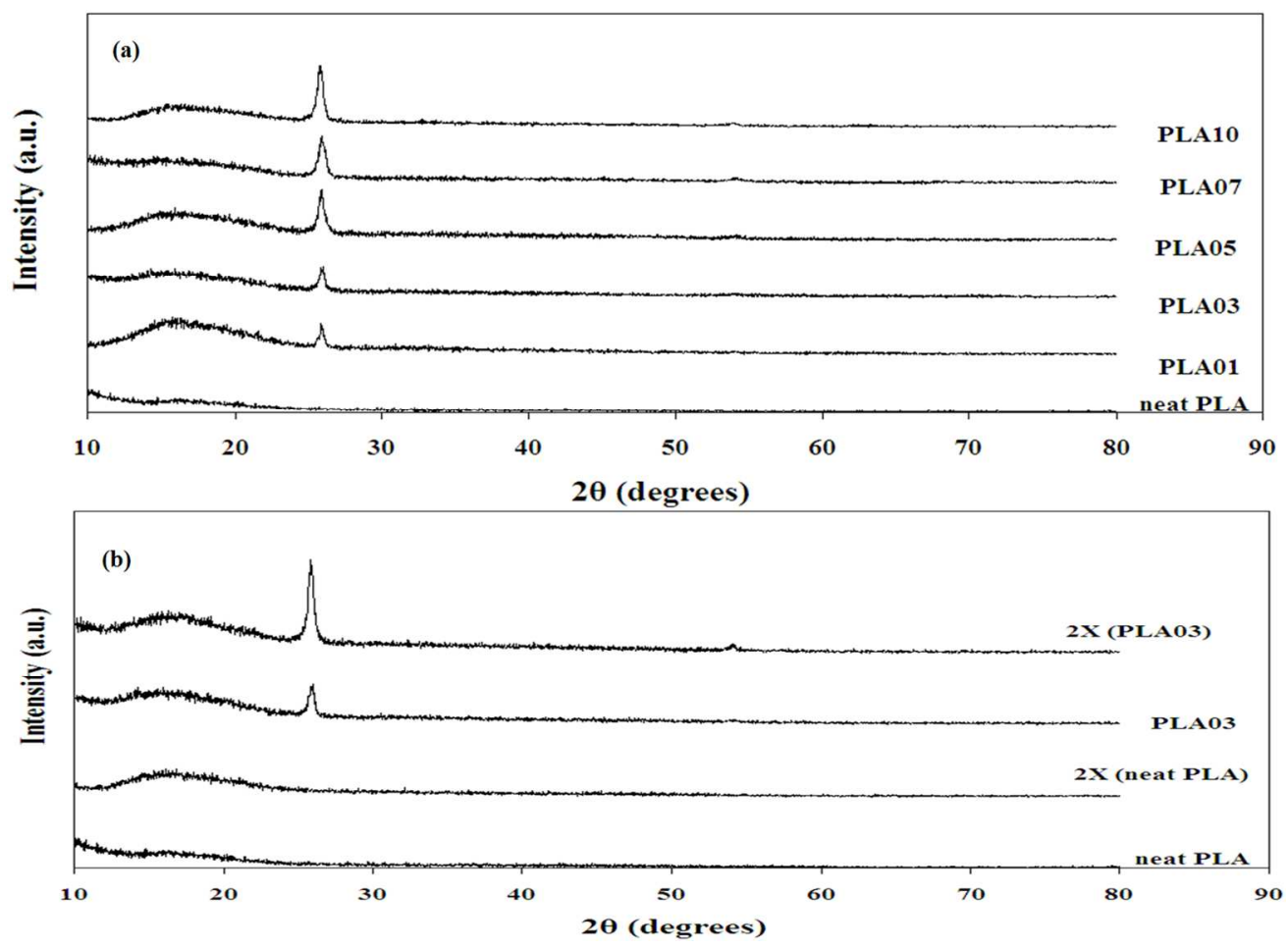

Fig. 1. Comparative XRD diffractograms of composites after compression moulding: 0-10 wt. \% NGP content (a), double extruded composites (b). $260 \times 189 \mathrm{~mm}(144 \times 144 \mathrm{DPI})$ 


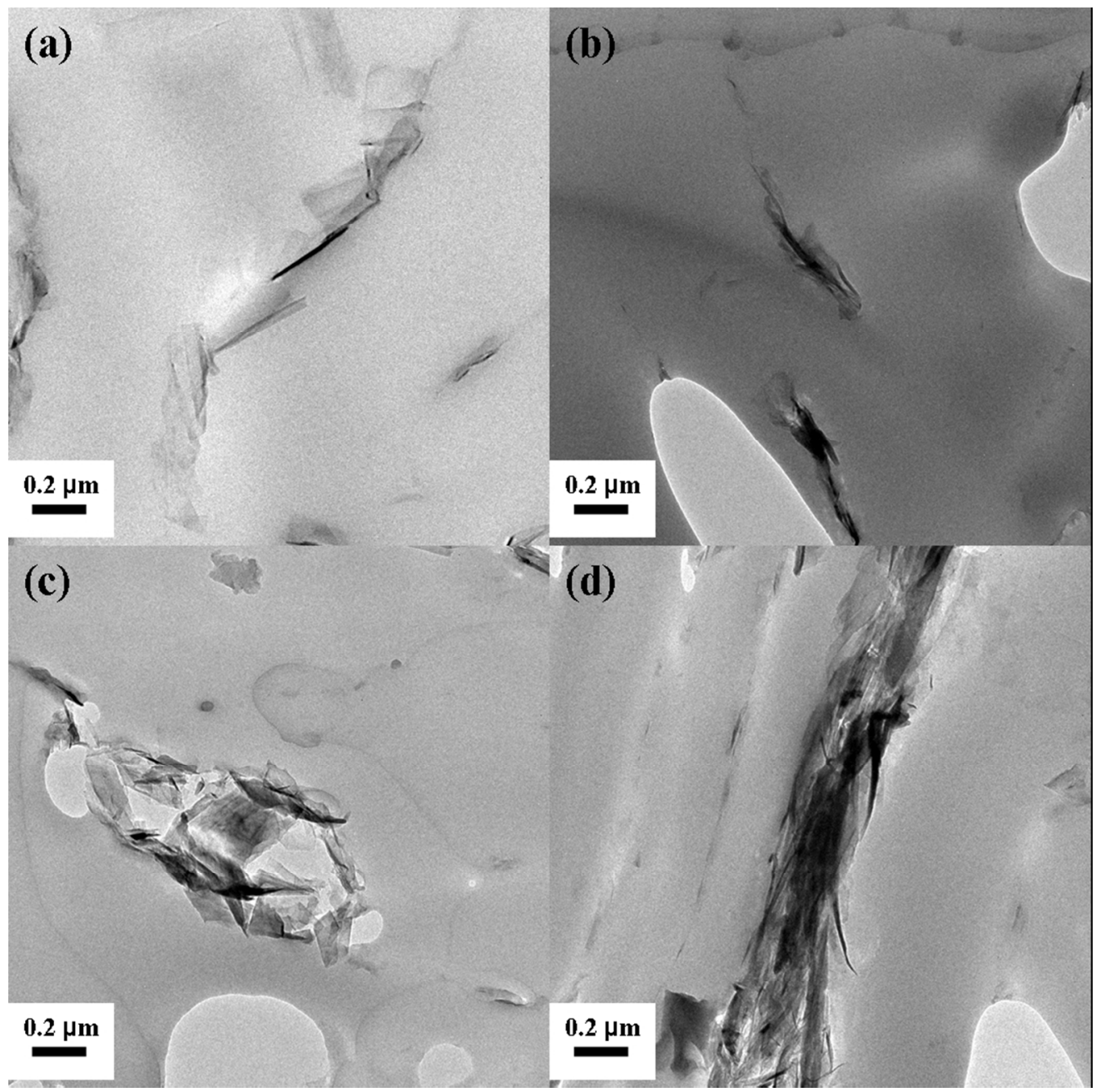

Fig. 2. TEM micrographs of PLA/NGP composites at $0.2 \mu \mathrm{m}$ magnification microtomed from compression moulded specimens: $1 \% \operatorname{NGP}(a, b), 3 \%(c, d), 5 \%(e, f), 7 \%(g, h), 10 \%(i, j)$. $180 \times 179 \mathrm{~mm}(150 \times 150 \mathrm{DPI})$ 


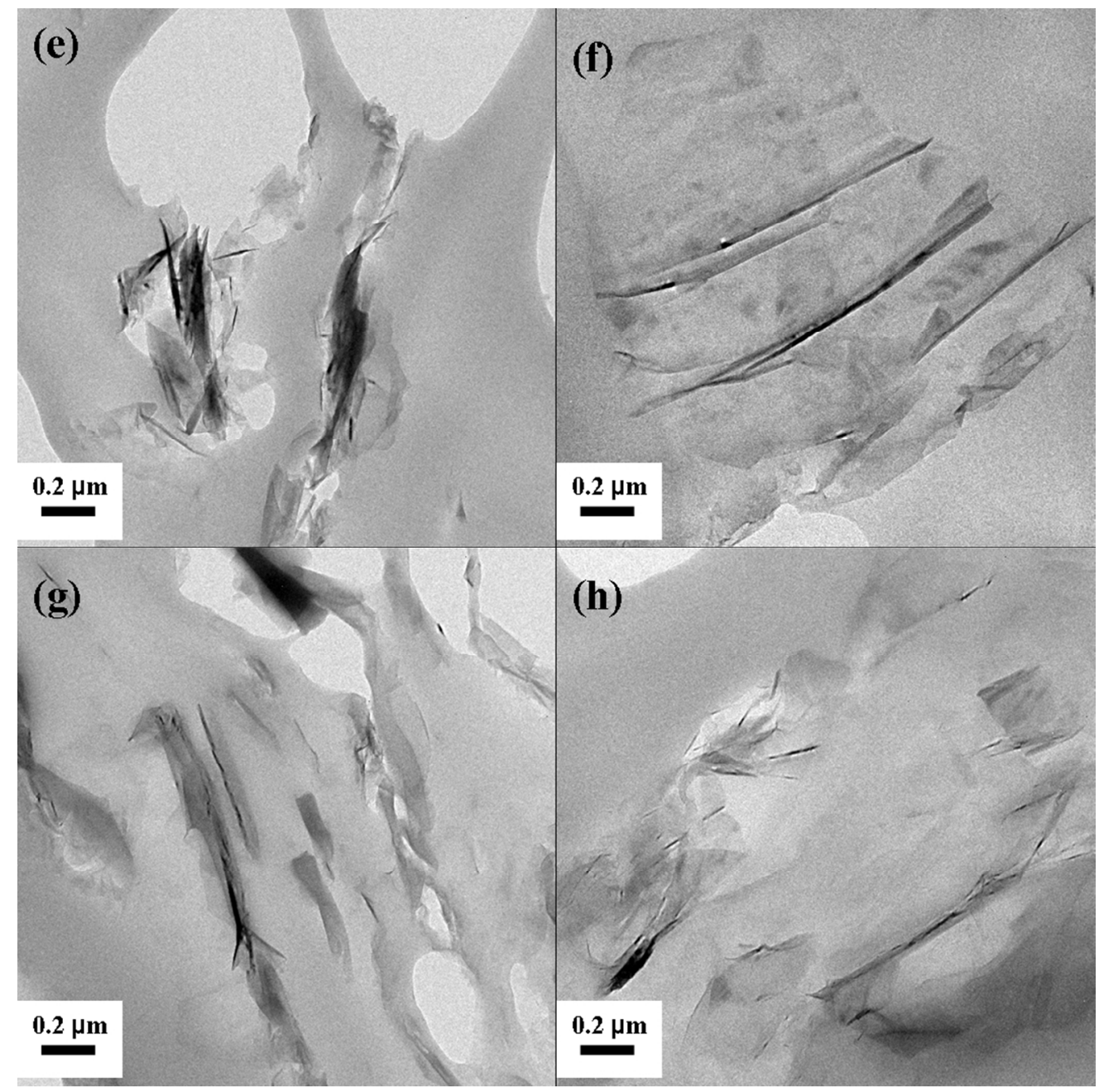

Fig. 2. TEM micrographs of PLA/NGP composites at $0.2 \mu \mathrm{m}$ magnification microtomed from compression moulded specimens: $1 \% \operatorname{NGP}(a, b), 3 \%(c, d), 5 \%(e, f), 7 \%(g, h), 10 \%(i, j)$. $180 \times 180 \mathrm{~mm}(150 \times 150 \mathrm{DPI})$ 
Fig. 2. TEM micrographs of PLA/NGP composites at $0.2 \mu \mathrm{m}$ magnification microtomed from compression moulded specimens: $1 \%$ NGP $(a, b), 3 \%(c, d), 5 \%(e, f), 7 \%(g, h), 10 \%(i, j)$. $180 \times 89 \mathrm{~mm}(150 \times 150 \mathrm{DPI})$ 


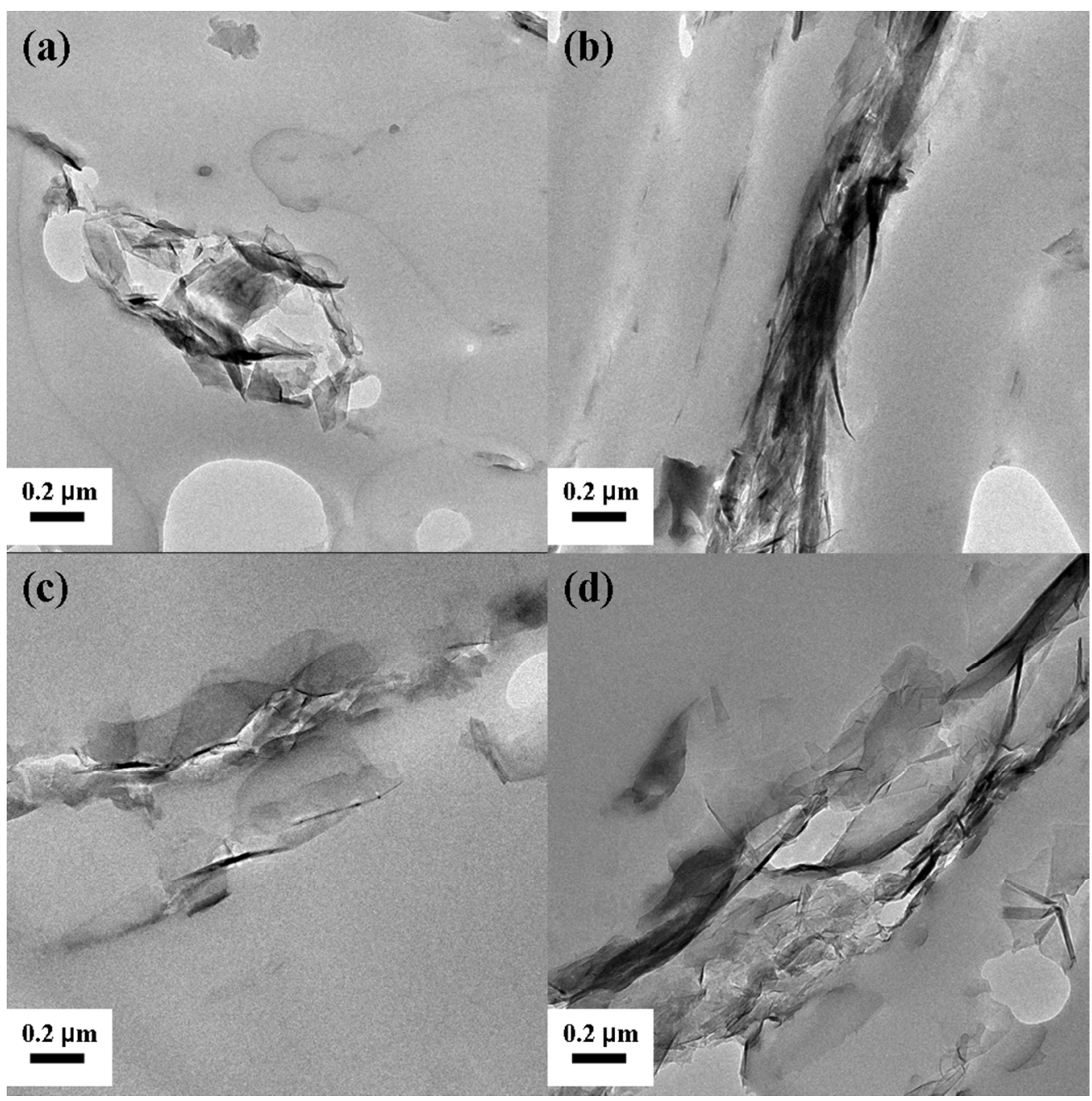

Fig. 3. TEM micrographs of PLA/NGP composites at $0.2 \mu \mathrm{m}$ magnification microtomed from compression moulded specimens: $3 \%$ NGP $(a, b), 2 X(3 \% N G P)(c, d)$. $179 \times 180 \mathrm{~mm}(150 \times 150 \mathrm{DPI})$ 


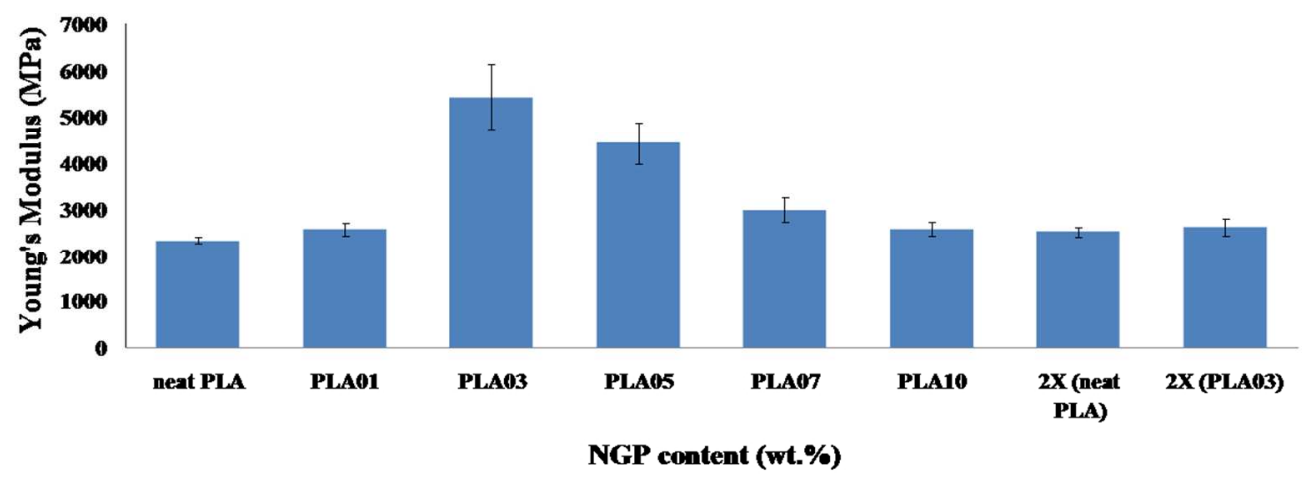

Fig. 4. Young's modulus of samples measured through tensile testing. $322 \times 118 \mathrm{~mm}(96 \times 96 \mathrm{DPI})$ 


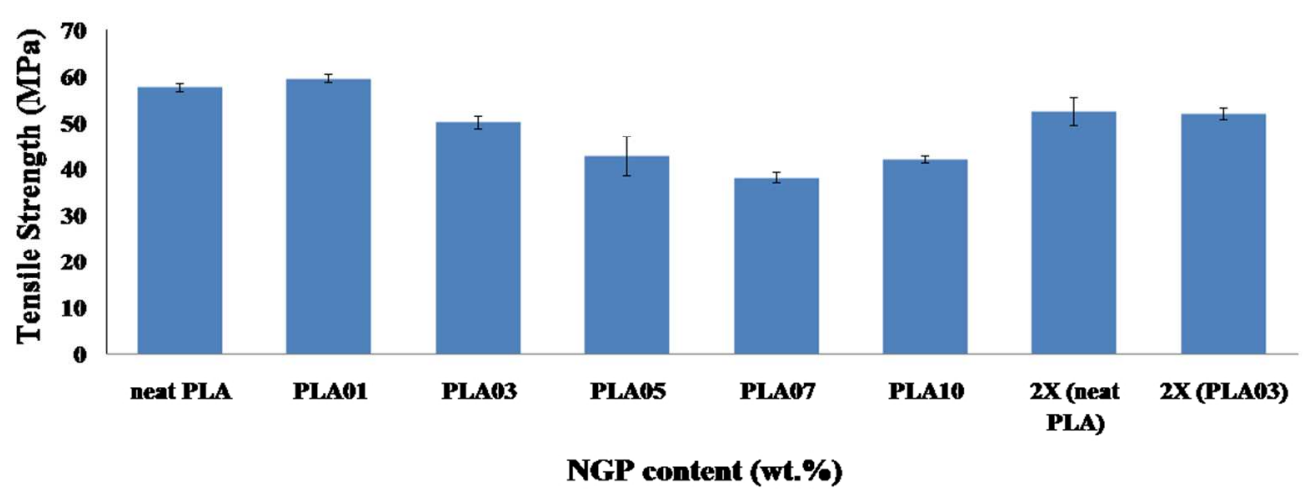

Fig. 5. Tensile strength of samples measured through tensile testing. $296 \times 109 \mathrm{~mm}$ (96 x 96 DPI) 


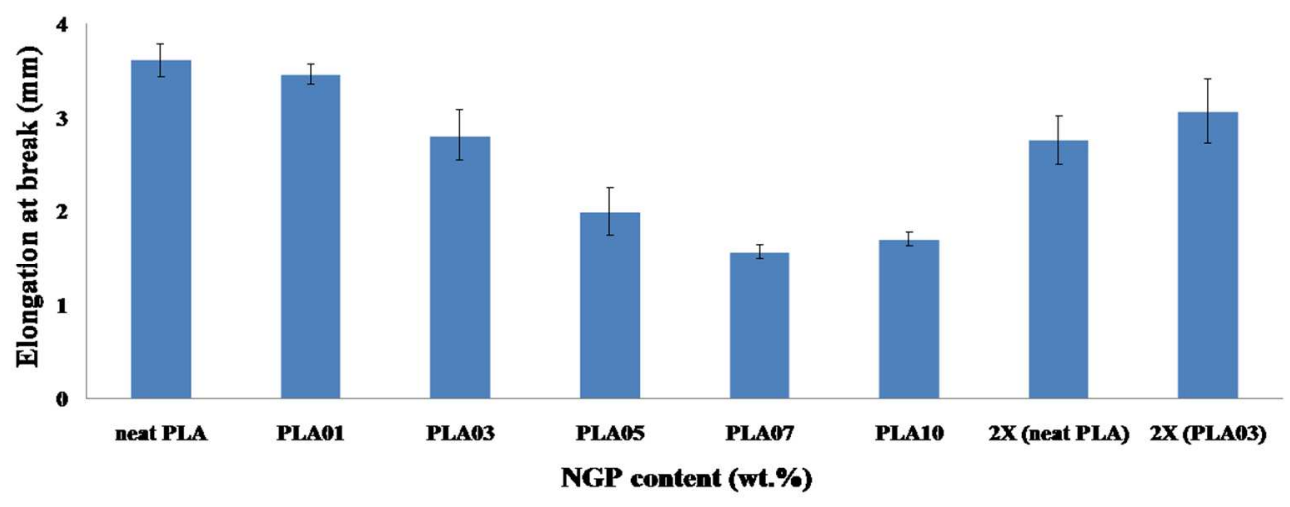

Fig. 6. Elongation of samples measured through tensile testing. $327 \times 125 \mathrm{~mm}(96 \times 96 \mathrm{DPI})$ 
Fig. 7. Comparative MDSC thermograms of composites: (a) single extruded samples during second heating cycle (b) double extruded vs. their single extruded counterparts during second heating cycle (c) single extruded samples during first heating cycle. $338 \times 190 \mathrm{~mm}(144 \times 144 \mathrm{DPI})$ 
Fig. 7. Comparative MDSC thermograms of composites: (a) single extruded samples during second heating cycle (b) double extruded vs. their single extruded counterparts during second heating cycle (c) single extruded samples during first heating cycle. $338 \times 190 \mathrm{~mm}(144 \times 144 \mathrm{DPI})$ 
Fig. 7. Comparative MDSC thermograms of composites: (a) single extruded samples during second heating cycle (b) double extruded vs. their single extruded counterparts during second heating cycle (c) single extruded samples during first heating cycle. $338 \times 190 \mathrm{~mm}(144 \times 144 \mathrm{DPI})$ 
Fig. 8. Comparative MDSC thermograms of composites: (a) single extruded samples during first cooling cycle (b) double extruded vs. their single extruded counterparts during first cooling cycle. $1058 \times 793 \mathrm{~mm}(120 \times 120 \mathrm{DPI})$ 
Fig. 8. Comparative MDSC thermograms of composites: (a) single extruded samples during first cooling cycle (b) double extruded vs. their single extruded counterparts during first cooling cycle. $1058 \times 793 \mathrm{~mm}(120 \times 120 \mathrm{DPI})$ 